\title{
Genotype by Environment Effects on Potato Mini-Tuber Seed Production in an Aeroponics System
}

\author{
Julián F. Mateus-Rodriguez ${ }^{1}$, Stef de Haan ${ }^{2, *}$ and Alfredo Rodríguez-Delfín ${ }^{3}$ \\ 1 Corporación Colombiana de Investigación Agropecuaria (CORPOICA), Km. 14 vía Mosquera \\ Cundinamarca, Mosquera, Apartado Aéreo 240142 Las Palmas, Colombia; \\ E-Mail: jmateus@corpoica.org.co \\ 2 International Potato Center (CIP), Avenida La Molina 1895, Apartado 1558, Lima 12, Peru \\ 3 Centro de Hidroponía y Nutrición Mineral-Universidad Agraria La Molina (UNALM), Apartado \\ 12-056, Lima 12, Peru; E-Mail: delfin@lamolina.edu.pe \\ * Author to whom correspondence should be addressed; E-Mail: s.dehaan@cgiar.org; \\ Tel.: +51-1-3496017; Fax: +51-1-3175326.
}

External Editor: Mick Fuller

Received: 1 September 2014; in revised form: 6 November 2014 / Accepted: 11 November 2014 / Published: 21 November 2014

\begin{abstract}
In order to evaluate the environmental effect on plant development and mini-tuber production of a diverse group of potato genotypes grown under an aeroponic system, a $\mathrm{G} \times \mathrm{E}$ interaction experiment was carried out in greenhouses located at CIP's experimental stations in La Molina (Lima) and Huancayo (Junín). Five contrasting environments were set-up and evaluated. A combined Analysis of Variance was performed for the variables "days to tuber set", "days to senescence" and "plant height". An Additive Main Effects and Multiplicative Interaction (AMMI) Analysis was performed for yield variables: mini-tuber "weight" and "number of mini-tubers" per plant. There was a high variation in all the responses to the treatments. "Days to tuber set" was influenced by genetic responses, temperature and greenhouse Photosynthetically Active Radiation intensity. Considerable increases in the length of the vegetative cycle and plant height were recorded for all genotypes, and these were particularly notable in the warmer coastal environments. AMMI analysis showed that yield variables were primarily influenced by the genotypic effect followed by the genotype by environment interaction effect. The Venturana variety (T2) was the best performing genotype with a total average mini-tuber "weight" of 644 g per plant while the Chucmarina variety (T1) performed best for the
\end{abstract}


variable "number of mini-tubers" with an overall average of 60.2 mini-tubers per plant. Both showed stability across different environments for these variables. The advanced clones T3 (395434.1), T5 (397077.16) and T6 (397073.16) showed stability for yield variables, but their performance was below the overall average of the trial. It is recommended that the environment and management should ideally be tailored to the genotype as this will result in significant yield gains.

Keywords: mini-tuber production; environment effect; genotypic effect

\section{Introduction}

Potato is a vegetatively propagated crop conserving varietal characteristics during successive generations [1]. This is advantageous in a genetic improvement program, but it has the disadvantage that seed tubers can favor the dissemination of diseases if quality control is not systematically monitored in a production program. Generally, potato tuber seed production schemes consist of three phases: (i) in vitro multiplication under laboratory conditions; (ii) pre-basic mini-tuber production under screen or greenhouse conditions; and (iii) basic seed tuber production under open-field conditions.

The production of pre-basic mini-tubers should be based on high-quality starting material, either disease-free in vitro plantlets or micro-tubers [2]. Screen- or greenhouse production of mini-tubers is commonly done by conventional methods that rely on solid substrates (basically peat and soil), with the inherent risk of infection from soil borne diseases and need for sterilization. Conventional substrate-based methods for pre-basic mini-tuber seed production frequently show low productivity. According to Daniels et al. [3], the average multiplication rate is 3-5 mini-tubers per plant, which contributes to raising the production costs of a seed potato production program.

Different alternative methods are available for the production of mini-tubers using soilless cultivation techniques [4-6]. The advantage of these systems lies in the possibility of controlling phytosanitary quality and tuber size. Also, depending on the system used, they make it possible to conduct staggered harvest without the need to eliminate plants, thereby increasing the number of mini-tubers per plant [7]. Hydroponics is a basic technique of soilless cultivation in which plants grow in a solution of water and nutrients. The need for the use of substrates is thus removed, as are the associated problems: heterogeneity, availability, disinfection, extraction of base materials, and waste disposal [8].

Aeroponics is a particular type of hydroponics, where the root system of the plants is confined to a dark environment without substrate, and is continually saturated with a mist spray of a water and nutrient solution [9]. Aeroponics for potato mini-tuber production is practiced throughout the world, including in Asia, Europe and Latin America for research purposes and commercial seeds production [10]. A commonality in all production environments relates to the strong influence of genotype, environment and genotype by environment interaction on yield [11,12]. Climate conditions, day-length, mineral content of solutions, and the genetic make-up of varieties are strong drivers of differential performance [13-16]. A particular challenge of aeroponics relates to the excessive growth 
of the foliage and root system, as well as the prolongation of the vegetative period [12]. These production constraints can be partially controlled through management, including pruning or fertilization practices.

Comprehension and identification of the causes of genotype by environment $(G \times E)$ interaction effects can help identify those elements that contribute to a better yield or performance of a specific variety in a given environment and can be used to identify ideal conditions and/or formulate crop management recommendations [17]. This research sought to evaluate the effect of the environment on the growth, development, and production of mini-tubers of a diverse group of genotypes cultivated under an aeroponics system for the production of potato mini-tubers.

\section{Materials and Methods}

\subsection{Location of the Experiment}

The experiment was conducted under greenhouse conditions at the experimental stations of the International Potato Center (CIP) in Peru: La Molina station in Lima (244 $\mathrm{m}$ altitude) and Huancayostation in Junín (3259 m altitude). The greenhouse dimensions were: $30 \mathrm{~m}$ long, $12 \mathrm{~m}$ wide, $8 \mathrm{~m}$ high and $16 \mathrm{~m}$ long, $5 \mathrm{~m}$ wide, $4 \mathrm{~m}$ high for the La Molina and Huancayo environments, respectively. Under conditions of intense heat, a $50 \%$ shade net was extended over the greenhouses. No greenhouse cooling or heating systems were used. Basically, the exposure to environments resulted from a combination of different seasons at each locality. Table 1 provides an overview of the locations, environments and seasons employed.

Table 1. Research locations, environments and seasons employed.

\begin{tabular}{ccccc}
\hline No. & Location & Code Assigned to Environment & Date of Planting & Season \\
\hline 1 & Lima & LM1 & 1 August, 2008 & Winter to summer \\
2 & Lima & LM2 & 9 November, 2008 & Spring to winter \\
3 & Lima & LM3 & 24 April, 2009 & Autumn to summer \\
4 & Huancayo & HY1 & 2 December, 2008 & Rainy season \\
5 & Huancayo & HY2 & 30 April, 2009 & Dry season \\
\hline
\end{tabular}

The LM1, LM2 and LM3 environments at the La Molina station were characteristic of the coastal region in mid-winter, mid-spring and beginning of autumn, respectively. The HY1 and HY2 environments at the Huancayo station were characteristic of the Peruvian highland conditions, coinciding with the rainy and dry seasons, respectively.

Table 2 presents a summary of climate variables. The overall maximum temperature in the greenhouse fluctuated between 27.2 and $28.8^{\circ} \mathrm{C}$ for all environments. With regard to the minimum greenhouse temperature, it was lower in the two highland environments (HY1 and HY2). The overall average relative humidity in the coastal environments was higher compared to the highland environments. Also, the overall PAR maximum average values were higher in the coastal as compared to the highland environments. Year-to-year climate variations per homologous seasons at each location were not evaluated in this study. 
Table 2. Summary of climate variables of the five different environments.

\begin{tabular}{ccccccc}
\hline Variable & & LM1 & LM2 & LM3 & HY1 & HY2 \\
\hline \multirow{2}{*}{ Greenhouse temperature $\left(\right.$ foliage) $\left({ }^{\circ} \mathrm{C}\right)$} & Maximum & 27.2 & 27.6 & 27.5 & 27.6 & 28.8 \\
& Minimum & 18.4 & 18.4 & 17.3 & 6.6 & 6.6 \\
& Maximum & 19.7 & 19.4 & 19.8 & 20.2 & 20.6 \\
Container temperature (roots) $\left({ }^{\circ} \mathrm{C}\right)$ & Minimum & 15.3 & 13.8 & 13.9 & 12.1 & 12.2 \\
Relative humidity $(\%)$ & Average & 71.4 & 70.7 & 72.8 & 63.1 & 61.5 \\
$\operatorname{PAR}\left(\mu \mathrm{mol} \cdot \mathrm{m}^{-2} \cdot \mathrm{s}^{-1}\right)$ & Maximum & 234.3 & 288.3 & 377.4 & 174.2 & 172.4 \\
\hline
\end{tabular}

\subsection{Genetic Material and Management}

Ten different genotypes were used: two and four advanced clones respectively from CIP's breeding populations for horizontal resistance to Phytophthora infestans (late blight) and adaptation to the lowlands tropics with combined virus resistance, one improved variety from Peru, two improved varieties in commercial use in Africa, and one Andean landrace from Peru. Table 3 lists the genetic material used and its main characteristics.

Table 3. Genotypes employed and their main characteristics.

\begin{tabular}{ccccc}
\hline Treatments & Cultivar & Population/Origin & Vegetative Period $^{\mathbf{I}}$ & $\begin{array}{c}\text { Genetic Weight in } \\
\text { Pedigree }\end{array}$ \\
\hline T1 & Chucmarina & B3C1 (CIP) & Moderately late & andigena \\
T2 & Venturana & B3C1 (CIP) & Moderately late & andigena \\
T3 & CIP 395434.1 & LTVR (CIP) & Semi-early & tuberosum \\
T4 & CIP 397036.7 & LTVR (CIP) & Early & andigena \\
T5 & CIP 397077.16 & LTVR (CIP) & Early & tuberosum \\
T6 & CIP 397073.16 & LTVR (CIP) & Early & tuberosum \\
T7 & Serranita & Peru & Moderately late & andigena \\
T8 & Tigoni & Kenya & Early & tuberosum \\
T9 & Victoria & Kenya & Early & tuberosum \\
T10 & Yana Imilla & Peru & Late & andigena \\
\hline \multicolumn{7}{c}{ under open field conditions. }
\end{tabular}

The research started with in vitro plantlets that were transplanted in trays with sterilized sand for proper root development and hardening. During the first 21 days, the moisture was maintained in the media through hand watering in combination with application of a nutrient solution. When the plants were ready for transplanting to the aeroponics system, they were extracted from the trays with the help of large tweezers, and the particles of sand adhering to the root were removed with a soft brush and sterilized water. Plants were placed in holes made on the lid of each container of the aeroponics system, taking care that the roots remained suspended inside as they were held in place with a small piece of sponge wrapped around the stem to prevent them from falling in. 


\subsection{The Aeroponics System}

The aeroponics system was set up in each greenhouse with $5 \mathrm{~m}$ long, $1.2 \mathrm{~m}$ wide and $0.8 \mathrm{~m}$ high containers made of wood and expanded plastic sheets. The nutrient solution was sprinkled inside the containers using nebulizers with a capacity of 30 liters per hour, which generated a micro-environment with high relative humidity in order to favor adequate growth and development of the roots suspended in the air. A 1200-L tank, buried at floor level, was used to store the nutrient solution for circulation though the closed system. A $0.75 \mathrm{HP}$ constant pressure pump was used to distribute the nutrient solution through the system using $3 / 4$ inches PVC piping. Inside each container, a $16 \mathrm{~mm}$ PE irrigation line was placed. Each line had four Naandan Jain nebulizers inserted. The nebulizing time of the aeroponics system was adjusted through visual observations, seeking to keep the roots moist and plants turgid. The time was set on three minutes of irrigation every five minutes throughout the 24 hours of daily operation. An irrigation controller, allowing the pump to switch on and off at the indicated times, was used.

The Potato La Molina ${ }^{\circledR}$ nutrient solution was used. This is a commercial solution formulated after several years of research at the Hydroponics and Mineral Nutrition Research Center of the National Agrarian University La Molina (UNALM). The formulation has two nutrition versions: A and B. The starting solution (A) was used from transplanting to up to 35 days. Its concentration $\left(\mathrm{mg} \cdot \mathrm{L}^{-1}\right)$ was: N 190, P 35, K 220, Ca 150; Mg 40; S 70; Fe 1.0; Mn 0.5; B 0.5; Zn 0.15; Cu 0.10 and Mo 0.05. A second nutrient solution (B) was used to achieve high tuberization rates. The concentration of $\mathrm{K}$ $\left(275 \mathrm{mg} \cdot \mathrm{L}^{-1}\right)$ was increased while the content of $\mathrm{N}\left(81 \mathrm{mg} \cdot \mathrm{L}^{-1}\right)$ was lowered. The basic management of the nutrient solution consisted of performing daily measurements and corrections of the $\mathrm{pH}$ and electrical conductivity (EC). The $\mathrm{pH}$ was kept in a range of 5.5-6.5 and the EC between 1.5 and $2.0 \mathrm{dS} / \mathrm{m}$. Sulfuric acid was used to adjust the $\mathrm{pH}$. A stock solution of $\mathrm{NaCl} 1 \mathrm{M}$ was used to increase the salinity of the nutrient solution. From the time the plants reached a height of 30 centimeters, it was necessary to use tutors and conduct basal pruning to guide the stems. All the genotypes were exposed to the same management conditions, including standard cultural and phytosanitary preventative controls for Phytophthora and Oidium using a commercial fungicide at $50 \%$ of the normal amount in the nutrient solution.

Harvesting of mini-tubers was conducted every 15 days. The starting point for the first harvest was when the first mini-tubers reached a minimum size of $15 \mathrm{~mm}$ (at least $12 \mathrm{~g}$ ).Hourly records were kept for the following variables: temperature $\left({ }^{\circ} \mathrm{C}\right)$, relative humidity $(\%)$, and Photosynthetically Active Radiation- $\left(\mathrm{PAR} ; \mu \mathrm{mol} \cdot \mathrm{m}^{-2} \cdot \mathrm{s}^{-1}\right)$ in each greenhouse and temperature $\left({ }^{\circ} \mathrm{C}\right)$ inside the containers. Measurements were taken with HOBO equipment (model U12-012). During crop development, the following variables were recorded: "days to tuberization", "days to senescence", and "plant height" (cm). Yield variables consisted of: "number of mini-tubers" per plant and "weight" in g per plant.

\subsection{Statistical Analysis}

For all environments, the genotypes were organized in a Complete Randomized Block Design (CRBD) with three replications. Each container represented one block/replication in a specific environment and the genotypes were the respective treatments. A total of 20 plants per genotype were 
planted for each replication. A homogeneity of variance test was performed for all variables. Next, a combined analysis for a CRBD was performed using a fixed model considering environment and genotypes as fixed effects. Once the prior analyses of the significance of the main effects and their interaction had been determined, the respective decomposition of simple effects was performed for the interaction in the combinations of the genotype factor at each level of the environment factor. Where significant differences were found, the Tukey test for separation of means with 5\% significance was carried out.

An Additive Main Effects and Multiplicative Interaction (AMMI) Analysis was carried out for the production variables: "number of mini-tubers" per plant and "weight" in g per plant. This analysis helps to unravel the individual performance of the genotypes and environments of the study. Furthermore, to explain whether there were interaction effects through the decomposition of the $\mathrm{G} \times \mathrm{E}$ interaction in multiplicative components using a principal components (PC) analysis. The AMMI model integrates the combined analysis of variance and the principal components analysis [18]. In the analysis, the genotypes and the environments are graphically and simultaneously represented on a biplot. This biplot is constructed based on the first two principal components of the analysis. The genotypes or environments that possess high coordinates for the first principal axis (positive or negative) have a greater contribution to the $G \times E$ interaction than the genotypes or environments with values close to zero. All the analyses were carried out with $\mathrm{R}$ statistical software.

\section{Results and Discussion}

\subsection{Effect of the Environment on Growth and Development}

Table 4 shows the mean squares of the combined Analysis of Variance (ANOVA) for the variables "days to tuber set", "days to senescence" and "plant height". Highly significant differences were observed for environments, genotypes, and genotype by environment interaction for all three variables. For those environments in which homogeneity of variances was established, a combined analysis was pursued: three environments for variable "days to tuber set" variable (Table 5) and four environments for the variables "days to senescence" and "plant height" variables (Tables 6 and 7).

Table 4. Mean squares of the combined ANOVA for key variables of crop development for 10 potato genotypes under aeroponics.

\begin{tabular}{cccccrr}
\hline Source of Variation & $\boldsymbol{D F}^{\mathbf{f}}$ & $\begin{array}{c}\text { Mean Square-Days } \\
\text { to Tuber Set }\end{array}$ & $\boldsymbol{D F}$ & $\begin{array}{c}\text { Mean Square -Days } \\
\text { to Senescence }\end{array}$ & $\begin{array}{c}\text { DF } \\
\text { Mean Square-Plant } \\
\text { Height }\end{array}$ \\
\hline Environments & 2 & $2783.4 * *$ & 3 & $25,300.4 * *$ & 3 & $218,840.6 * *$ \\
Blocks/environments & 6 & $22.32 *$ & 8 & $60.51 *$ & 8 & 12.22 \\
Gen & 9 & $2789.3 * *$ & 9 & $5604.7 * *$ & 9 & $46,121.8 * *$ \\
Gen/environments & 18 & $587.6 * *$ & 27 & $1416.2 * *$ & 27 & $6065.2 * *$ \\
Overall error & 54 & 5.3 & 72 & 3.6 & 72 & 21.4 \\
CV (\%) & & 4.9 & & 0.8 & 230.2 & 174.8 \\
General mean & & 47.3 & & 23.6 & \\
\hline
\end{tabular}

${ }^{\mathbf{I}}$ Degrees of Freedom; ** $p<0.01 ; * p<0.05$. 
Table 5. G $\times$ E interaction effects for the "days to tuber set" (days) variable.

\begin{tabular}{ccccccccccc}
\hline Environment & T1 & T2 & T3 & T4 & T5 & T6 & T7 & T8 & T9 & T10 \\
\hline LM1 & $38.3 \mathrm{~b}$ & $41.3 \mathrm{c}$ & $24.0 \mathrm{~b}$ & $43.4 \mathrm{~b}$ & $31.7 \mathrm{a}$ & $41.3 \mathrm{a}$ & $58.3 \mathrm{~b}$ & $53.3 \mathrm{~b}$ & $68.3 \mathrm{~b}$ & $53.3 \mathrm{~b}$ \\
LM3 & $16.7 \mathrm{c}$ & $53.3 \mathrm{~b}$ & $16.7 \mathrm{c}$ & $16.7 \mathrm{c}$ & $16.7 \mathrm{~b}$ & $16.7 \mathrm{~b}$ & $73.3 \mathrm{a}$ & $68.3 \mathrm{a}$ & $73.3 \mathrm{a}$ & $43.3 \mathrm{c}$ \\
HY1 & $68.7 \mathrm{a}$ & $74.7 \mathrm{a}$ & $53.3 \mathrm{a}$ & $68.3 \mathrm{a}$ & $16.0 \mathrm{~b}$ & $15.7 \mathrm{~b}$ & $73.3 \mathrm{a}$ & $68.3 \mathrm{a}$ & $73.7 \mathrm{a}$ & $68.8 \mathrm{a}$ \\
\hline
\end{tabular}

* Number in column followed by the same letter do not differ significantly at $P=0.05$.

Table 6. $G \times$ E interaction effects for the "days to senescence" (days) variable.

\begin{tabular}{ccccccccccc}
\hline Environment & T1 & T2 & T3 & T4 & T5 & T6 & T7 & T8 & T9 & T10 \\
\hline LM1 & $235.3 \mathrm{~b}$ & $238.3 \mathrm{c}$ & $162.7 \mathrm{~d}$ & $235.3 \mathrm{~b}$ & $162.7 \mathrm{c}$ & $163.3 \mathrm{c}$ & $240.3 \mathrm{~b}$ & $240.0 \mathrm{~b}$ & $239.0 \mathrm{c}$ & $224.0 \mathrm{~b}$ \\
LM2 & $275.3 \mathrm{a}$ & $291.3 \mathrm{a}$ & $251.3 \mathrm{a}$ & $293.3 \mathrm{a}$ & $251.3 \mathrm{a}$ & $260.7 \mathrm{a}$ & $291.3 \mathrm{a}$ & $275.3 \mathrm{a}$ & $291.3 \mathrm{a}$ & $251.3 \mathrm{a}$ \\
LM3 & $218.7 \mathrm{~d}$ & $253.0 \mathrm{~b}$ & $172.0 \mathrm{c}$ & $230.7 \mathrm{c}$ & $230.7 \mathrm{~b}$ & $230.0 \mathrm{~b}$ & $230.7 \mathrm{c}$ & $230.0 \mathrm{~d}$ & $251.3 \mathrm{~b}$ & $172.0 \mathrm{c}$ \\
HY1 & $224.0 \mathrm{c}$ & $236.7 \mathrm{c}$ & $225.0 \mathrm{~b}$ & $237.7 \mathrm{~b}$ & $161.3 \mathrm{c}$ & $161.3 \mathrm{c}$ & $189.7 \mathrm{~d}$ & $234.3 \mathrm{c}$ & $224.0 \mathrm{~d}$ & $221.7 \mathrm{~b}$ \\
\hline
\end{tabular}

* Number in column followed by the same letter do not differ significantly at $P=0.05$

Table 7. G $\times$ E interaction effects for the "plant height" $(\mathrm{cm})$ variable.

\begin{tabular}{ccccccccccc}
\hline Environment & T1 & T2 & T3 & T4 & T5 & T6 & T7 & T8 & T9 & T10 \\
\hline LM1 & $337.8 \mathrm{a}$ & $369.1 \mathrm{a}$ & $295.3 \mathrm{a}$ & $357.2 \mathrm{a}$ & $106.6 \mathrm{~b}$ & $92.4 \mathrm{~b}$ & $352.1 \mathrm{a}$ & $332.8 \mathrm{a}$ & $293.3 \mathrm{a}$ & $217.8 \mathrm{a}$ \\
LM2 & $181.0 \mathrm{~b}$ & $192.3 \mathrm{~b}$ & $119.0 \mathrm{c}$ & $190.0 \mathrm{c}$ & $119.0 \mathrm{a}$ & $58.7 \mathrm{c}$ & $282.3 \mathrm{~b}$ & $271.0 \mathrm{~b}$ & $210.7 \mathrm{~b}$ & $214.0 \mathrm{a}$ \\
LM3 & $187.0 \mathrm{~b}$ & $189.3 \mathrm{~b}$ & $158.3 \mathrm{~b}$ & $210.7 \mathrm{~b}$ & $113.3 \mathrm{ab}$ & $108.7 \mathrm{a}$ & $204.0 \mathrm{c}$ & $225.0 \mathrm{c}$ & $210.0 \mathrm{~b}$ & $125.0 \mathrm{~b}$ \\
HY2 & $30.3 \mathrm{c}$ & $141.7 \mathrm{c}$ & $35.3 \mathrm{~d}$ & $36.3 \mathrm{~d}$ & $15.7 \mathrm{c}$ & $16.0 \mathrm{~d}$ & $205.0 \mathrm{c}$ & $114.7 \mathrm{~d}$ & $57.0 \mathrm{c}$ & $15.7 \mathrm{c}$ \\
\hline
\end{tabular}

* Number in column followed by the same letter do not differ significantly at $P=0.05$.

Tables 5-7 show the $\mathrm{G} \times \mathrm{E}$ interaction effects for the "days to tuber set", "days to senescence" and "plant height" variables. With reference to the moderately late to late genotypes (T1, T2, T7 and Y10), it was observed that under conditions of the LM3 environment, a comparatively short time period to tuber initiation was recorded for the genotypes T1 (Chucmarina) and T10 (Yana Imilla), with 16.7 and 43.3 days, respectively (Table 5). On the other hand, for the genotypes T7 (Serranita) and T2 (Venturana) tuber initiation was earliest in the LM1 environment with 58.3 and 41.3 days, respectively. In the HY1 environment, these four genotypes required more time for tuber initiation.

For the early genotypes (T3, T4, T5, T6, T8 and T9), a differentiated behavior was observed when grown under LM1 versus LM3 environmental conditions. The genotypes T3 (395434.1), T4 (397036.7), T5 (397077.16) and T6 (397073.16) significantly reduced the number of days to tuber initiation to 16.7 days. On the other hand, the genotypes T8 (Tigoni) and T9 (Victoria) increased the number of days required from 53.3 and 58.3 days to 68.3 and 73.3 days, respectively. The response of T8 (Tigoni) and T9 (Victoria) grown under LM3 versus HY1 environment conditions did not produce significant differences. T3 (395434.1) and T4 (397036.7) showed a significant increase in the number of days needed for tuber initiation in the HY1 environment. The strongest environmental effect was experienced by the genotypes T3 (395434.1) and T4 (397036.7).

Low temperatures $\left(12-16^{\circ} \mathrm{C}\right)$ stimulate tuberization [19] and such conditions occur mainly in the highland environment. However, in the HY1 environment this response was observed only for two out of 10 of the genotypes evaluated (T5 and T6). Conversely, the LM3 environment presented the highest temperature averages (above $20^{\circ} \mathrm{C}$ ) at the beginning of the growing cycle and it was in this 
environment that the lowest tuberization induction time occurred for most of the genotypes. This was particularly so at the beginning of the plants' development cycle when most genotypes in environment LM 3 showed rapid tuber set. Radiation is an important factor influencing tuberization and may partially explain the early tuber set observed in the LM3 environment, even though the average temperatures were comparatively high $[15,20]$.

The moderately late and late genotypes experienced significant variations in their response for "days to senescence" (Table 6). In the LM2 environment, the longest vegetative cycle was observed for all genotypes. Particularly, the genotypes T2 (Venturana) and T7 (Serranita) were very late taking up to 291.3 days to senescence. Similarly, long vegetative periods were recorded for the T1 (Chucmarina) and T10 (Yana Imilla) genotypes in the LM2 environment. Yet, these same genotypes showed the lowest number of "days to senescence" needed to reach maturity in the LM3 environment with 218.7 and 172 days, respectively. The genotypes T2 (Venturana) and T7 (Serranita) needed the least number of "days to senescence" to reach maturity in the HY1 environment with 236.7 and 198.7 days, respectively.

Also, for the group of early genotypes the longest life cycles were observed in the LM2 environment, reaching a maximum of 293.3 days for the genotypes T4 (397036.7). Overall, the genotypes T3 (395434.1), T5 (397077.16) and T6 (397073.16) showed the strongest environmental effect for "days to senescence". The genotype T3 (395434.1) expressed a low number of "days to senescence" with 162.7 and 172 days in the LM1 and LM3 environments, respectively. Also, the genotypes T5 (397077.16) and T6 (397073.16) were early maturing in the LM1 and HY1 environments with 163.3 and 161.3 "days to senescence", respectively. Contrary to earliness attributed under field growing conditions, the genotypes T8 (Tigoni) and T9 (Victoria) did not show precocity under aeroponics management in any of the environments.

There was an increase in the vegetative cycle for all the genotypes grown with aeroponics as compared to what was expected considering reported maturity under field conditions. This is consistent with results obtained by Otazú and Chuquillanqui [12] who reported an increase of up to 30 days for the potato varieties Canchan, Perricholi and Yungay grown in an aeroponics system as compared with cultivation in pots in conditions of the central Andean highlands of Peru. Likewise, Kang et al. [21] also reported an increase in the vegetative period of potato plants when grown in an aeroponics system. They [21] concluded this effect was due to the high availability of nutrients, especially nitrogen. The LM2 environment had warm conditions for at least seven months of the growing season, causing an unusual lengthening of the vegetative periods of all genotypes. These results are similar to those found by Khedher and Ewing [22] who observed a delay in the maturing of 11 potato clones cultivated in a greenhouse under heat-stress conditions.

Table 7 provides an overview of the $\mathrm{G} \times \mathrm{E}$ interaction effect for the variable "plant height". For the moderately late and late genotypes it was observed that all were tallest in the LM1 environment. The overall tendency for the genotypes T1 (Chucmarina) and T2 (Venturana) was similar across the different environments with the tallest and the smallest plants recorded in the LM1 and HY2 environments respectively. The plant height of the genotypes T7 (Serranita) and T10 (Yana Imilla) was statistically the same for the LM3 and HY2 and LM1 and LM2 environments, respectively.

For the early genotypes, the strongest environmental effect for the variable "plant height" variable was observed for the genotypes T3 (395434.1), T4 (397036.7), T8 (Tigoni) and T9 (Victoria). For 
these genotypes, the tallest "plant height" was recorded in the LM1 environment and the lowest "plant height" in the HY2 environment. The environmental effect of HY2 significantly reduced the magnitude of the response variable for all the genotypes. The genotypes T5 (397077.16) and T6 (397073.16) showed significant differences for "plant height" across environments but contrary to all other genotypes reached maximum height in the LM2 and LM3 environments, respectively.

The highest records for the variable "plant height" occurred in the warmest environments (Coast). In the highland environment (HY2), which presented events of low night temperatures, genotypes consistently had their lowest records for the variable "plant height". Wolf et al. [23] emphasize that warm temperatures cause a greater translocation of photosynthates towards the vegetative organs (stems and leaves) and conclude that there is a significant effect of temperature on the plant height and final number of potato leaves. Other authors have also pointed out that high temperatures induce plants with thin stems, small leaves, and greater length of internodes [24]. The temperature of the root environment of the HY2 environment presented average records below $10{ }^{\circ} \mathrm{C}$ during the initial months of plant development. This was due to the presence of frost in the external environment, which could have significantly affected the final plant height of the genotypes evaluated. Indeed, Cooper [25] highlights that mean root temperatures below $10^{\circ} \mathrm{C}$ can give rise to potato plants of less than $8 \mathrm{~cm}$ in height. It is also clear that aeroponics results in much higher plant height than would normally be the case under open field conditions.

\subsection{Effect of the Environment on Weight and Number of Tubers Per Plant}

Table 8 shows the AMMI analysis for yield variables taking into consideration all five study environments: "weight" (grams per plant) and "number of mini-tubers" per plant. Highly significant differences were observed for the principal effects for genotypes, environment, and for the $\mathrm{G} \times \mathrm{E}$ interaction. This shows that the genotypes had a differential behavior for yield variables across the different environments.

The AMMI analysis for the yield variable "weight" of the 10 genotypes evaluated in the different environments determined that $49.3 \%$ of the total sum of squares was attributable to genotypic effects, while the environmental and the $\mathrm{G} \times \mathrm{E}$ interaction effects explained $12.8 \%$ and $20.5 \%$, respectively. Clearly the greatest attribution of the variation in "weight" was caused by the genotypic effect, possibly due to the ample diversity of genetic material used. The magnitude of the sum of squares of the $\mathrm{G} \times \mathrm{E}$ interaction was almost 2.5 times lower than that attributed to the genotypic effect, but 1.6 times greater than the sum of squares attributed to the environment. This clearly indicates different responses of the genotypes across the different environments. The first three principal components' axis (PCA1, PCA2 and PCA3) were all highly significant (Table 8). The first axis of the analysis of interaction components (PCA1) explained or captured $63.6 \%$ of the sum of squares of the interaction, and the second axis (PCA2) 22.8\%. These results show that the effect of the $\mathrm{G} \times \mathrm{E}$ interaction was explained for $86.4 \%$ by the first two principal components. 
Table 8. AMMI analysis for the yield variables "weight" (g/plant) and "number of mini tubers" per plant for 10 genotypes evaluated in five different environments.

\begin{tabular}{|c|c|c|c|c|c|c|c|c|}
\hline \multirow[t]{2}{*}{ Source of Variation } & \multicolumn{4}{|c|}{ Weight (g/Plant) } & \multicolumn{4}{|c|}{$\begin{array}{c}\text { Number of Mini-Tubers } \\
\text { Per Plant }\end{array}$} \\
\hline & D.F. ${ }^{\mathrm{I}}$ & $\begin{array}{l}\text { Sum of } \\
\text { squares }\end{array}$ & Mean squares & Explains & D.F. & $\begin{array}{l}\text { Sum of } \\
\text { squares }\end{array}$ & $\begin{array}{l}\text { Mean } \\
\text { squares }\end{array}$ & Explains \\
\hline Corrected total & 149 & $19,043,207$ & & & 149 & 110,338 & & \\
\hline Environments & 4 & $2,437,402$ & $609,350 * *$ & $12.80 \%$ & 4 & 8042 & $2010.6 * *$ & $7.30 \%$ \\
\hline Blocks (environ.) & 10 & $2,531,269$ & $25,317 * *$ & $13.30 \%$ & 10 & 1177 & 117.7 & $1.10 \%$ \\
\hline Genotypes & 9 & $9,395,130$ & $1,043,903 * *$ & $49.30 \%$ & 9 & 67,732 & $7525.7 * *$ & $61.40 \%$ \\
\hline $\mathrm{G} \times \mathrm{E}$ interaction & 36 & $3,897,583$ & $108,266 * *$ & $20.50 \%$ & 36 & 27,583 & $766.2 * *$ & $25.00 \%$ \\
\hline PCA1 & 12 & $2,480,433.1$ & $206,702.76 * *$ & $63.60 \%$ & 12 & $16,014.7$ & $1334.55 * *$ & $58.10 \%$ \\
\hline PCA2 & 10 & 887,684 & $88,768.4 * *$ & $22.80 \%$ & 10 & 8662.6 & $866.85 * *$ & $31.40 \%$ \\
\hline PCA3 & 8 & $418,285.4$ & $52,285.67 * *$ & $10.70 \%$ & 8 & 2166.9 & $270.86 * *$ & $7.90 \%$ \\
\hline Residual & 90 & 781,823 & $18,530.1$ & $4.10 \%$ & 90 & 5804 & 64.5 & $5.30 \%$ \\
\hline $\mathrm{CV} \%$ & & 21 & & & & 16.4 & & \\
\hline General mean & & 444.2 & & & & 48.99 & & \\
\hline
\end{tabular}

${ }^{\mathrm{I}}$ Degrees of Freedom; $* * p<0.01 ; * p<0.05$.

The biplot in Figure 1A makes it possible to link the genotypes and environments based on the $\mathrm{G} \times \mathrm{E}$ interaction for the variable "weight" (g/plant). The biplot has four quadrants in which genotypes and environments with PCA values of the same sign interact positively. In other words, the grouping of the genotypes and the environments in the same quadrant indicates a positive association between them. The environments are located in the four sections and represented by a vector line while the genotypes are represented by diamonds. For the variable "weight", the genotype T1 showed the best adaptation in the environment LM1, the genotype T4 in LM2, while the genotypes T2, T8 and T9 were more closely aligned with the environment LM3. Likewise, the genotypes T7 and T10 performed best in the environment HY1, and the genotypes T3, T5 and T6 in the environment HY2. Genotypes situated near the center of biplot axis were least affected by the $\mathrm{G} \times \mathrm{E}$ interaction. Consequently the genotypes T2, T5, and T6 can be considered the most stable in their final response for the variable "weight", while the genotypes T1, T4, T7, and T9 had a greater effect of the environment on their response.

The biplot in Figure 1B shows the "weight" variable per plant according to the coordinates of PCA1. The dotted vertical line represents the average weight $(x=444.2 \mathrm{~g} / \mathrm{plant})$. Again, the environments are indicated by a vector line and the genotypes by diamonds. Crossa et al. [26] report that the genotypes and environments with high coordinates on PCA1 contribute to a greater extent to the $\mathrm{G} \times \mathrm{E}$ interaction while the genotypes and environments with PCA1 coordinates close to zero have little participation in this effect. In accordance with this interpretation, it can be observed that genotypes T2 and T8 contributed little to the interaction. 
Figure 1. Biplots for the yield variable total average mini-tuber "weight" (g/plant). (A) Graphical representation of the two principal components explaining the $\mathrm{G} \times \mathrm{E}$ interaction; (B) Graphical representation of the first principal component as a function of mini-tuber "weight".
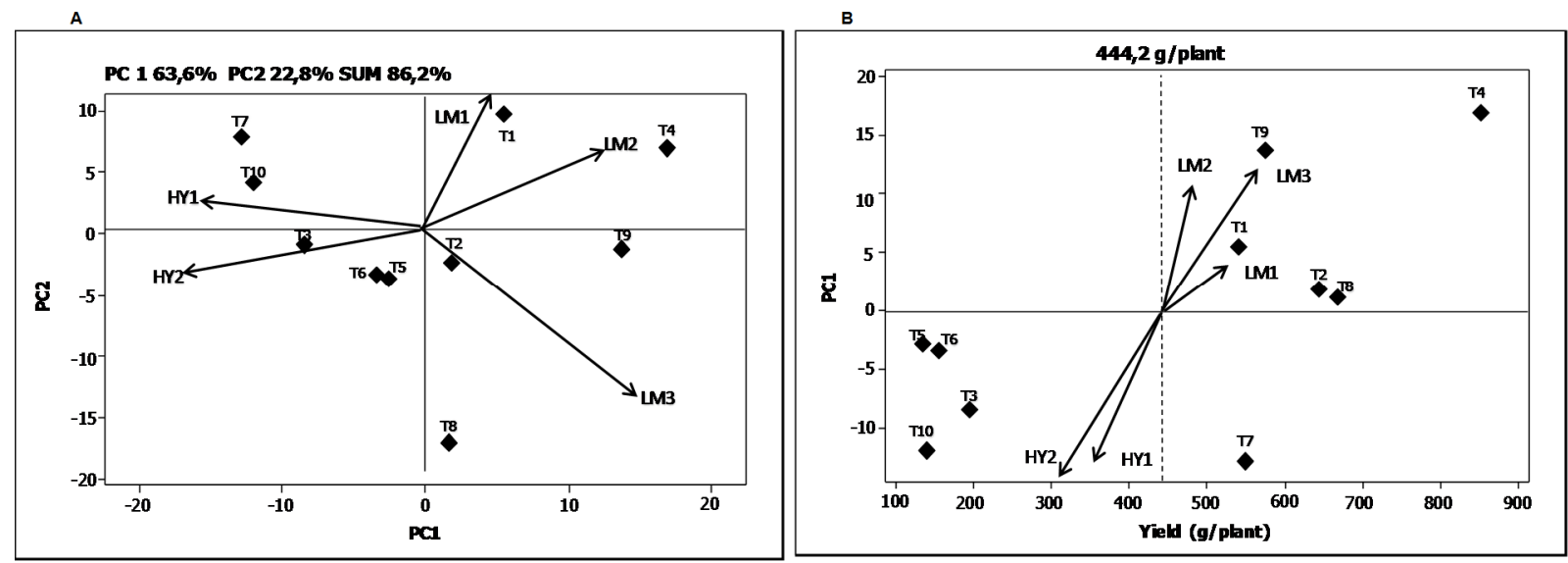

The genotypes T4, T8, and T2 had the highest values for "weight" per plant. The environment LM1 contributed least to the interaction while the environment LM3 was found to be where the variable "weight" per plant was best expressed. On the contrary, the environment HY2 was where the lowest averages values were registered. Both the environments HY2 and HY1 contributed significantly to the interaction effect. Yan et al. [17] point out that those environments that exhibit an angle of less than $90^{\circ}$ between them have the quality of accommodating the genotypes in a similar way. Consequently, it can be observed that the environments LM1, LM2 and LM3 versus HY1 and HY2 resulted in comparatively similar expressions for the variable "weight" per plant. With reference to the "number of mini-tubers" per plant, the AMMI analysis determined that $61.4 \%$ of the total sum of squares was attributable to genotypic effects while the environmental and the $\mathrm{G} \times \mathrm{E}$ interaction effects explained $7.3 \%$ and $25.0 \%$, respectively (Table 8 ). The magnitude of the sum of squares of the $\mathrm{G} \times \mathrm{E}$ interaction was almost 2.4 times lower than that attributed by the genotypic effect but 3.4 times higher than the sum of squares ascribed to the environmental effect. The first three principal components' axis (PCA1, PCA2 and PCA3) were all highly significant. The first axis of the principal component analysis (PC1) captures $58.1 \%$ of the sum of squares of the interaction, and the second axis (PC2) $31.4 \%$. These results show that the effect of the $\mathrm{G} \times \mathrm{E}$ interaction for "number of mini-tuber" per plant was explained $89.5 \%$ by the first two principal components.

The genotypes T1 and T4 showed the best response in the environment LM1, the genotype T2 genotype in the environment HY2, and the genotypes T7 and T3 in the environment HY1 (Figure 2A). The genotypes T1, T3, T5 and T6 were stable in their response in the five environments for the variable "number of mini-tuber" per plant. On the other hand, the genotypes T2, T8, T9, and T10 experienced the environmental effect to the greatest extent. 
Figure 2. Biplots for the yield variable total average "number of mini-tubers" per plant. (A) Graphical representation of the two principal components explaining the $\mathrm{G} \times \mathrm{E}$ interaction; (B) Graphical representation of the first principal component as a function of the "number of mini-tubers" per plant.
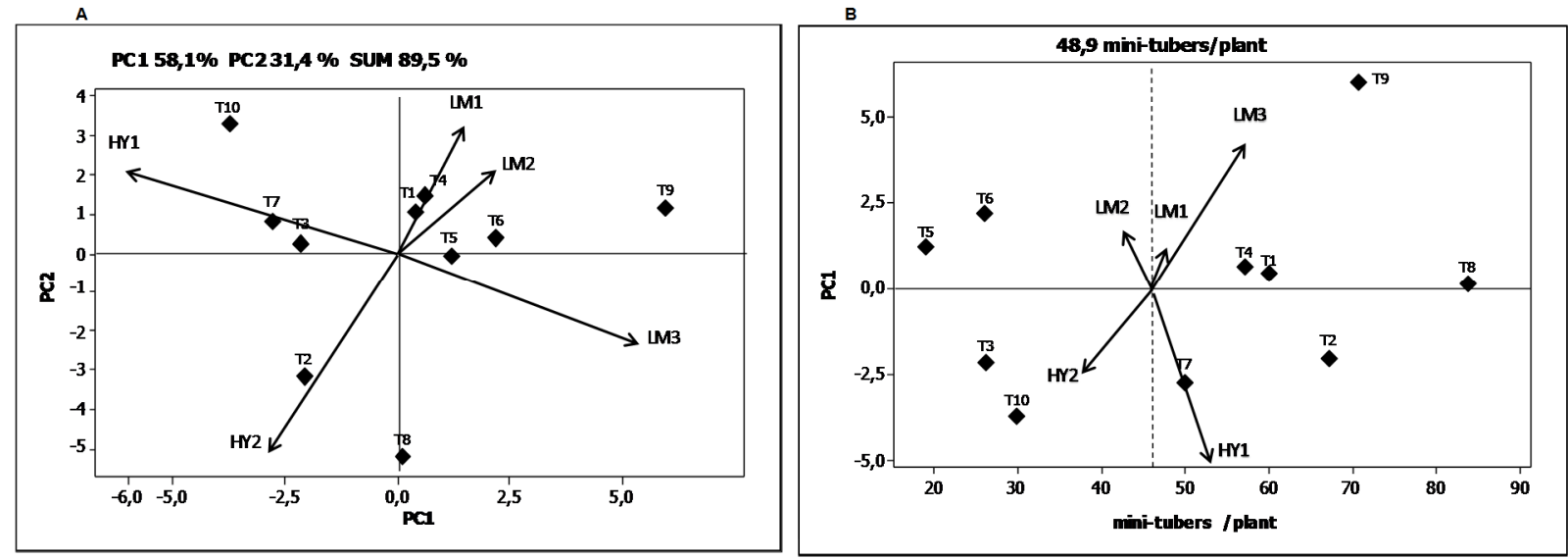

Figure 2B shows the average "number of mini-tubers" per plant according to the coordinates of the PCA1. The dotted vertical line represents the average "number of mini-tubers" per plant $(x=48.9$ mini-tubers/plant). In this figure, the genotypes that are close have similar adaptation. Consequently, genotypes like T1 and T4 have a similar adaptation. The genotypes which contributed to a greater extent to the $\mathrm{G} \times \mathrm{E}$ interaction were $\mathrm{T} 9, \mathrm{~T} 6, \mathrm{~T} 7$ and $\mathrm{T} 10$. The environments that contributed the most to a differential $\mathrm{G} \times \mathrm{E}$ interaction were HY1 followed by LM3. The highest average "number of mini-tubers" per plant was obtained in the LM3 environment followed by HY1. The lowest average "number of mini-tubers" per plant was obtained in the coastal environment during the summer season (LM2) and the highland environment during the dry season (HY2). In the environment LM2, the daytime greenhouse temperatures were above $30{ }^{\circ} \mathrm{C}$ during some months of crop development. On the other hand, the HY2 environment had night temperatures dropping to under $5{ }^{\circ} \mathrm{C}$ during the early months of crop development. Both environments can be considered extreme and notably affected the number of mini-tubers per plant obtained.

\section{Conclusions}

Under the diverse environmental conditions of this $\mathrm{G} \times \mathrm{E}$ interaction trial, an ample response of the different genotypes cultivated in the aeroponics system was found for the variable "days to tuber set". Increases in the length of the vegetative cycle in aeroponics as compared to open field conditions were evident for all the genotypes in all the environments. A greater duration of the number of "days to senescence" was particularly notable in the comparatively warm environment LM2 (spring-winter). There was considerable variation in the "plant height" for all the test environments. The low temperatures of the root zone presented in environment HY2 during the dry season negatively affected the development of the potato plants.

Variations concerning the yield variables "weight" and "number of mini-tubers" per plant were predominantly attributable to the genotypic effect. The three coastal environments (LM1, LM2, LM3) generally outperformed the highland environments (HY1, HY2) for the variable mini-tuber "weight". 
The Venturana variety (T2) was particularly stable for the variable "weight" with a comparatively high yield of $644 \mathrm{~g}$ per plant. The genotypes T3, T5, and T6 also proved to be stable for the variable mini-tuber "weight", but their yields were below the overall average. Overall, the environment LM3 (autumn-spring) provided optimal conditions to obtain high numbers of mini-tubers. The Chucmarina variety (T1) proved to be particularly stable with a high total average number of 60.2 mini-tubers per plant. The genotypes T3, T5 and T6 also demonstrated stability for the variable "number of mini-tubers" per plant, although their production was below the overall average.

It is clear that potato mini-tuber production as an intermediate step between in vitro multiplication and open field tuber seed production is highly influenced by genotypic, environmental and interaction effects. The provision of an adequate production environment, including management conditions, is vital for maximizing the mini-tuber yield potential. If possible, the environment and management should be adapted and tailored to the genotype as this is likely to result in significant yield gains. Future research on genotype by environmental interactions should preferably include fertility and tuberization induction regimes so that our understanding of the sink-source energy investment can be better understood.

\section{Acknowledgments}

We gratefully acknowledge the financial support from FONTAGRO (Regional Fund for Agricultural Development).

\section{Author Contributions}

Julián F. Mateus-Rodriguez and Stef de Haan both contributed equally to the overall conception and writing of the article. Alfredo Rodríguez-Delfin had an important role in guiding the field research and revising the manuscript.

\section{Conflicts of Interest}

The authors declare no conflict of interest.

\section{References}

1. Simmonds, N.W. A review of potato propagation by means of seed, as distinct from clonal propagation by tubers. Potato Res. 1997, 40, 191-214.

2. Chuquillanqui, C.; Tenorio, J.; Salazar, L.F. Producción de semilla de papa por hidroponía. In Alternativas al Uso del Bromuro de Metilo para la Producción de Semilla de Papa de Calidad; CIP, Ed.; International Potato Center (CIP): Lima, Perú, 2007; pp. 26-34.

3. Daniels, J.; Pereira, A.; Fortes, G.R.L. Verticalização da Produção de Batata-Semente por Produtores de Agricultura Familiar no Rio Grande do Sul; Embrapa Clima Temperado: Pelotas, Brasil, 2000; p. 4.

4. Muro, J.; Díaz, V.; Goni, J.L.; Lamsfus, C. Comparasion of hydroponic culture and culture in a peat/sand mixture and the influence of nutrient solution and plant density on seed potato yields. Potato Res. 1997, 40, 431-438. 
5. Ranalli, P. Innovative propagation methods in seed tuber multiplication programmes. Potato Res. 1997, 40, 439-453.

6. Ritter, E.; Angulo, B.; Riga, P.; Herrán, J.; Relloso, J.; San José, M. Comparison of hydroponic and aeroponic cultivation systems for the production of potato minitubers. Potato Res. 2001, 44, $127-135$.

7. Loomen, W.J.M. Basic Studies on the Production and Performance of Potato Minitubers. Ph.D. Thesis, Wageningen Agricultural University, Wageningen, The Netherlands, 1995.

8. Rodríguez-Delfín, A.; Chang, M.; Hoyos, M.; Falcón, F. Manual Práctico de Hidroponía, 2nd ed.; Centro de Investigación de Hidroponía y Nutrición Mineral-Universidad Nacional Agraria La Molina: Lima, Perú, 2004; p. 100.

9. Christie, C.B.; Nichols, M.A. Aeroponics: A Production system and research tool. Acta Hortic. 2004, 648, 289-291.

10. Mateus-Rodriguez, J.; de Haan, S.; Andrade-Piedra, J.; Maldonado, L.; Hareau, G.; Barker, I.; Chuquillanqui, C.; Otazú, V.; Frisancho, R.; Bastos, C.; et al. Technical and economic analysis of aeroponics and other system for potato mini-tuber production in latin America. Am. J. Potato Res. 2013, 90, 357-368.

11. Farran, I.; Mingo-Castel, A.M. Potato minituber production using aeroponics: Effects of Plant density and harvesting intervals. Am. J. Potato Res. 2006, 83, 47-53.

12. Otazú, V.; Chuquillanqui, C. Producción de Papa de Calidad por Aeroponia. In Alternativas al Uso del Bromuro de Metilo para la Producción de Semilla de Papa de Calidad; Centro Internacional de la Papa: Lima, Perú, 2007; pp. 35-45.

13. Ewing, E.E. Potato. The Physiology of Vegetable Crops; Wien, H.C., Ed.; CAB International: Wallingford, UK, 1997; pp. 295-344.

14. Haverkort, A.J. Ecology of potato cropping systems in relation to latitude and altitude. Agric. Syst. 1990, 32, 251-272.

15. Menzel, C.M. Tuberization in potato at high temperatures: Interaction between temperature and irradiance. Ann. Bot. 1985, 55, 35-39.

16. Midmore, D.J. Potato production in the tropics. In The Potato Crop: The Scientific Basis for Improvement, 2nd ed.; Chapman \& Hall: London, UK, 1992; pp. 728-793.

17. Yan, W.; Hunt, L.A.; Sheng, Q.; Szlavnics, Z. Cultivar evaluation and mega-environment investigation based on the GGE biplot. Crop Sci. 2000, 40, 597-605.

18. Yan, W.; Hunt, L.A. Interpretation of Genotype $\times$ Environment Interaction for Winter Wheat Yield in Ontario. Crop Sci. 2001, 41, 19-25.

19. Ewing, E.E. Heat stress and the tuberization stimulus. Am. Potato J. 1981, 58, 31-49.

20. Menzel, C.M. The potato as a potential crop for the lowlands tropics. Trop. Agric. 1984, 61, $162-166$.

21. Kang, J.G.; Yang, S.Y.; Kim, S.Y. Effects of nitrogen levels on the plant growth, tuberization and quality of potatoes grown in aeroponics. J. Korean Soc. Hortic. Sci. 1996, 37, 761-766.

22. Khedher, M.B.; Ewing, E.E. Growth analysis of eleven potato cultivars grown in the greenhouse under long photoperiods with and without heat stress. Am. Potato J. 1985, 62, 537-554.

23. Wolf, S.; Marani, A.; Rudich, J. Effect of temperature and photoperiod on assimilate partitioning in potato plants. Ann. Bot. 1990, 66, 513-520. 
24. Steward, F.C.; Moreno, U.; Roca, W.M. Growth, form, and composition of potato plants as affected by environment. Ann. Bot. 1981, 48, 1-45.

25. Cooper, A.J. Root Temperature and Plant Growth, a Review; Commonwealth Agricultural Bureaux: Slough, UK, 1973; p. 73.

26. Crossa, J.; Gauch, H.G.; Zobel, R.W. Additive main effects and multiplicative interaction analysis of two international maize cultivar trials. Crop Sci. 1990, 30, 493-500.

(C) 2014 by the authors; licensee MDPI, Basel, Switzerland. This article is an open access article distributed under the terms and conditions of the Creative Commons Attribution license (http://creativecommons.org/licenses/by/4.0/). 